\title{
1 Chronic lithium treatment alters the excitatory/inhibitory balance of synaptic networks and reduces mGluR5-PKC signaling
}

3

4 5

6

Khayachi $A^{1}$., Ase A. $R^{1}$., Liao $C^{1,2}$, Kamesh $A^{1}$., Kuhlmann $\mathrm{N}^{1}$., Schorova $\mathrm{L}^{3}$., Chaumette $\mathrm{B}^{4,5}$., Dion $\mathrm{P}^{1}$., Alda $\mathrm{M}^{6}$., Séguéla $\mathrm{P}^{1}$., Rouleau G.A. ${ }^{1,2 *}$ \& Milnerwood A. ${ }^{1 *}$.

${ }^{1}$ Montreal Neurological Institute, Department of Neurology \& Neurosurgery, McGill University, Montréal, Quebec, Canada.

${ }^{2}$ Department of Human Genetics, McGill University, Montréal, Quebec, Canada.

${ }^{3}$ McGill University Health Center Research Institute, Montréal, Quebec, Canada.

${ }^{4}$ Université de Paris, Institut de Psychiatrie et Neuroscience of Paris (IPNP), INSERM U1266, GHU Paris Psychiatrie et Neurosciences, Paris, France.

${ }^{5}$ Department of Psychiatry, McGill University, Quebec, Canada.

${ }^{6}$ Department of Psychiatry, Dalhousie University, Halifax, Nova Scotia, Canada.

\section{* Corresponding Authors:}

Dr Austen J. Milnerwood, PhD \& Dr. Guy A. Rouleau, MD, PhD, FRCPC, OQ

Department of Neurology and Neurosurgery

McGill University

Montréal, Québec, Canada H3A 2B4

E-mail: $\underline{\text { austen.milnerwood@ mcgill.ca \& guy.rouleau@ mcgill.ca }}$

Running title: Lithium shifts the synaptic network balance toward inhibition. 


\section{ABSTRACT}

Bipolar disorder (BD) is characterized by cyclical alternations between mania and depression, often comorbid with psychosis, and suicide. The mood stabilizer lithium, compared to other medications, is the most efficient treatment for prevention of manic and depressive episodes. The pathophysiology of $\mathrm{BD}$, and lithium's mode of action, are yet to be fully understood. Evidence suggests a change in the balance of excitatory/inhibitory activity, favouring excitation in BD. Here, we sought to establish a holistic appreciation of the neuronal consequences of lithium exposure in mouse cortical neurons and identify underlying mechanisms. We found that chronic (but not acute) lithium treatment significantly reduced intracellular calcium flux, specifically through the activation of the metabotropic glutamatergic receptor mGluR5. This was associated with altered phosphorylation of PKC and GSK3 kinases, reduced neuronal excitability, and several alterations to synapse function. Consequently, lithium treatment shifts the excitatory/inhibitory balance in the network toward inhibition. Together, the results revealed how lithium dampens neuronal excitability and glutamatergic network activity, which are predicted to be overactive in the manic phase of BD. Our working model of lithium action enables the development of targeted strategies to restore the balance of overactive networks, mimicking the therapeutic benefits of lithium, but with reduced toxicity. 


\section{INTRODUCTION}

Bipolar disorder (BD) is a major psychiatric illness affecting 1-3\% of the population worldwide and one of the top 10 causes of disability $(1,2)$. BD starts in adolescence and has a life-long course, characterized by frequently disabling episodes of mania and depression, often associated with psychosis and suicide (3). The etiology of BD is complex and unclear, with genetic and environmental factors implicated. Currently, except for very rare cases, no monogenic cause has been consistently identified, and genome-wide association study (GWAS) hits have been found in varied biological processes, including pathways related to intracellular signal transduction, glutamate synaptic function, hormone signaling, and immune system regulation (4-6). The unknown cause and apparent genetic heterogeneity of $\mathrm{BD}$ are a challenge to research efforts, especially those aimed at developing appropriate disease models.

Lithium is an effective treatment for mania and has been consistently shown to reduce suicide and overall mortality (7). Despite its narrow therapeutic range and potential side effects such as tremor, polyuria, decreased thyroid function, and renal toxicity in a minority of patients (8), lithium remains the first line treatment for prevention of both manic and depressive episodes in BD. For many patients, it is the most effective mood stabilizer $(9,10)$, and in addition to reducing suicide risk, it often enables patients to regain social and occupational function (7). Despite the widespread use of lithium as a BD treatment for over 60 years, the mode of action needs to be better understood, as does the reason why it is effective in only $\sim 30 \%$ of $B D$ patients $(11,12)$.

Studies aimed at elucidating lithium's mode of action have found macroscopic changes in brain structure (13) and alterations at the cellular level (14). For the latter, it has been shown that acute lithium administration increases glutamate signaling $(15,16)$. In contrast, longer-term chronic treatment over 6-7 days confers protection against glutamate-induced excitotoxicity, by reducing NMDA receptor-dependent calcium flux (17). It has also been shown that lithium alters various intracellular signaling cascades, by decreasing second messenger and calcium signaling, while inhibiting several enzymes and kinases such as glycogen synthesis kinase 3 (GSK3), extracellularregulated kinase (ERK)/mitogen-activated protein kinase (MAPK) and inositol monophosphate phosphatase (IMPase) $(14,18,19)$. The resulting alterations to intracellular signaling likely also converge upon the regulation of gene expression, synaptic transmission and plasticity, neuroprotection, and circadian biology.

Several genomic studies correlated specific loci with lithium responsiveness (20), suggesting a shared genetic predisposition both to disease and response to treatment. Single nucleotide polymorphisms (SNPs) in the PLCG1 gene have been associated with response to lithium, indicating that the phospholipase C (PLC)-phosphatidylinositol4,5-biphosphate (PIP2)-inositol triphosphate (IP3) signaling pathway may be an important target of lithium. Interestingly, our unpublished data (72) report an association between a SNP in the GRM5 gene encoding the metabotropic glutamate receptor 5 (mGluR5) and response to lithium suggesting that mGluR5 activity and downstream PLCIP3 signaling is also involved in lithium's therapeutic action. Other studies have found SNPs associated with BD in the GRIN2A(6) and GRIA2 genes that encode NMDA and AMPA receptor subunits, respectively. Intriguingly, only SNPs in GRIA2 were associated with lithium responsiveness $(5,21)$, suggesting that lithium alters the regulation of $\mathrm{Ca}^{2+}$-permeable AMPA receptors. Beyond genomic association, it remains unclear how lithium interacts with mGluR5, PLCG1 and GluA2 signaling to produce the beneficial outcome in lithium-responsive patients. 
Here, we sought to establish a holistic appreciation of the neuronal consequences of chronic lithium exposure in mouse cortical neurons and begin to determine the underlying mechanisms. We performed messenger RNA (mRNA) sequencing in neurons treated chronically with lithium and discovered altered transcriptional regulation of genes involved in glutamate receptor trafficking and intracellular calcium signaling. We found that chronic (but not acute) lithium treatment significantly reduced excitatory receptor-mediated intracellular calcium flux, specifically through the mGluR5 receptor. This was associated with altered phosphorylation of PKC and GSK3 kinases, reduced neuronal excitability, and several alterations to synapse function. Specifically, chronic lithium exposure reduced excitatory synapse activity and density, while increasing inhibitory synapse activity and density. Consequently, lithium treatment altered the excitatory/inhibitory (E/I) balance in the network, favouring inhibition. Together, the results shed light on how lithium may dampen neuronal excitability and glutamatergic network activity, which are predicted to be overactive in the manic phase of BD (22-24).

In addition, this discovery strengthens the potential clinical use of lithium to treat disorder with altered excitatory/inhibitory network activity such as epilepsy and several forms of autism. This study could also help to develop targeted strategies to restore the balance of overactive networks, mimicking the therapeutic benefits of lithium, but with reduced toxicity. 


\section{MATERIALS AND METHODS}

112

\section{Primary neuronal cultures and animals}

Cortical neurons were prepared from wild-type (WT) embryonic (E15.5) C57BL/6 mice as previously described (25). Animals were maintained within the Centre for Neurological Disease Modeling according to the Canadian Council on Animal Care regulations (AUP 2017-7888B). Briefly, cortical neurons were plated in Neurobasal medium (ThermoFisher 21103049) supplemented with $1 \times$ B27 (ThermoFisher 1750044), 1x glutaMax (ThermoFisher 35050061) on 60-mm dishes or 12-mm glass coverslips (VWR) pre-coated with poly-D-Lysine ( $0.1 \mathrm{mg} \mathrm{mL-1}$; Sigma). Neurons (600,000 cells per 60$\mathrm{mm}$ dish or 80,000 cells per 12 -mm coverslip) were then used at $18-20$ days in vitro (DIV).

\section{Drug treatment}

The therapeutic range of $\mathrm{LiCl}$ (lithium) treatment is between $0.75-1.5 \mathrm{mM}$. In this study, neurons were treated chronically with $\sim 1.5 \mathrm{mM} \mathrm{LiCl}$ (Sigma L9650) for 7 days starting at 11 DIV post-differentiation. As controls, neurons were treated with $\sim 1.5 \mathrm{mM}$ of NaCl (Sigma S5886) to keep the same amount of chloride in the dish as neurons treated with LiCl. Experiments were performed at 18 to $20 \mathrm{DIV}$.

\section{Data manipulation and statistical analyses}

Statistical analyses were performed using GraphPad Prism software (GraphPad software, Inc). All data are expressed as mean \pm standard error of the mean (s.e.m.). Paired t-tests (Fig 5A,B,C), parametric unpaired t-tests (Figs: 2C-G; 5D-F; Supplementary Figs: 3B; 4C,f; 5A-C) or non-parametric Mann-Whitney tests (Figs: 2H; 3B-E; 4; Supplementary Fig. 2A-C) were used to compare medians of two sets. One-sample t-tests were used with hypothetical value 100 for control (Figs: 3G; 5G, H; Supplementary Fig: 2D, E). Normality for all groups was verified using the Shapiro-Wilk tests and $p<0.05$ was considered significant.

\section{Data availability}

All relevant data are in the figures and supplementary figures. Raw data could be requested from the corresponding author.

A detailed "Materials and Methods" section can be found in the supplementary information. 


\section{RESULTS}

Chronic lithium treatment alters the expression of genes involved in synaptic activity, calcium signaling and neuronal excitability.

To identify the cellular processes altered by long-term exposure to lithium, we used a concentration designed to match those used in clinical practice. We examined whether there were detectable changes to neuronal gene expression induced by chronic lithium ( $\mathrm{cLiCl}$ ) treatment, using whole transcriptome sequencing in cortical neuron cultures at 18 DIV. Thirty genes were differentially expressed following 7 days of $\mathrm{CLiCl}$ treatment, relative to control (Fig. 1a and Supplementary Fig. 1). Using Reactome and GO analyses of gene clusters, we determined which pathways were significantly altered by $\mathrm{CLiCl}$ treatment. We identified pathways associated with trafficking of AMPA receptors, glutamate binding, activation of AMPA receptors and synaptic activity $(P=9.7 E-5)$. Calcium ion signaling $(\mathrm{P}=4.9 \mathrm{E}-4)$, CREB phosphorylation and RAS signaling $(\mathrm{P}=2.5 \mathrm{E}-4$ and $\mathrm{P}=2.8 \mathrm{E}-4)$ pathways were also implicated, as were pathways related to neurotransmission by chemical synapses $(P=1.1 \mathrm{E}-$ 3; Fig. 1B).

\section{Sub-toxic lithium treatment reduces spine density and alters dendritic spine morphology}

The therapeutic window for lithium is very narrow $(0.5$ to $\sim 1.5 \mathrm{mM})$ and the line between efficacy and toxicity is fine. It is proposed that lithium is toxic above $2 \mathrm{mM}$ (26); thus, we confirmed that our chronic lithium treatment at $\sim 1.5 \mathrm{mM}$ for 7 days had no detectable toxicity, as assayed by a cell viability test, in primary cortical neurons (Fig. 2C).

Excitatory synapses develop their specialized synaptic structures as they mature, over a similar timeframe in vivo and in primary culture. Immature postsynaptic protrusions, filopodia and thin spines, re-appear on dendrites between 4 \& 7 DIV after excitatory neurites have regenerated, and new contacts begin to form between axons and dendrites. As postsynaptic structures mature, they become shorter, fatter, and mushroom-like. By 21 DIV spine densities stabilize, with $80-90 \%$ of protrusions exhibiting mature morphology (27-29). Several studies have suggested lithium treatment leads to dendritic spines morphological changes (30-32). To determine whether chronic lithium treatment affects dendritic spine density and maturation, we analyzed the presence and morphology of dendritic protrusions in GFP-filled neurons after CLiCl treatment (Fig. 2A, B).

$\mathrm{CLiCl}$ treatment slightly reduced the density of protrusions in mouse cortical neurons (Fig. 2D; control $8.34 \pm 0.21$; cLiCl $7.33 \pm 0.21 / 10 \mu \mathrm{m}$ ) suggesting a reduction in the number of excitatory synapses. Analyses of the morphology of the remaining protrusions showed a significant reduction of $\sim 5.3 \%$ in the number of mature spines (mushroom spine type, see supplementary Methods for spine characterization guidelines; Fig. 2E). No changes occurred in the number of stubby spines ( $25 \%)$, but the percentage of immature spines (thin and filopodia spines) increased by $\sim 5 \%$ in $\mathrm{cLiCl}$-treated neurons (Fig. 2F, G), matching the reduction in mature protrusions. In addition, we observed a tendency towards a reduction in the mean head diameter of mature spines with $\mathrm{CLiCl}$ treatment, from $\sim 0.68 \mu \mathrm{m}$ to $\sim 0.64 \mu \mathrm{m}$ (Fig. $2 \mathrm{H}$ ). Together, the data show that cLiCl treatment results in smaller and fewer mature spines, indicating that lithium affects either spine maturation or maintenance of spine maturity in primary mouse cortical neurons.

\section{Lithium induces excitatory and inhibitory synaptic changes}


To examine whether the $\mathrm{CLiCl}$ induced changes to synapse densities reflecting the results obtained with spines in Fig. 2, we assayed for pre- and post-synaptic markers of excitatory and inhibitory synapses. To estimate excitatory synapse number, we quantified the density, intensity and colocalization of the presynaptic vesicular glutamate transporter 1 (VGluT1) and postsynaptic density protein 95 (PSD95; Fig. 3A, C). PSD95 puncta density was significantly reduced by $\mathrm{CLiCl}$ treatment (control $18.9 \pm 1.5 ; \mathrm{cLiCl} 12.9 \pm 0.9$ puncta/10 $10 \mathrm{~m}$ ), in agreement with the reduction in protrusion density and number of mature spines in neurons treated with $\mathrm{CLiCl}$ (Fig. 3C, D). Further, there were significantly fewer VGluT1/PSD95 co-clusters in cLiCl-treated neurons (control $5.9 \pm 0.5 ; \mathrm{cLiCl} 4.5 \pm$ 0.4 co-clusters $/ 10 \mu \mathrm{m}$; Fig. 3D), indicative of a reduction in excitatory synapse number after cLiCl treatment. VGluT1 (and VGAT, see below) puncta intensity was increased in remaining CLiCl-treated clusters (Supplementary Fig. 2B, C; VGlut1: control: $10.97 \pm 0.3$; cLiCl: $13.41 \pm 0.5$ a.u; VGAT: control, $12.91 \pm 0.4 ; \mathrm{LiCl}, 17.07 \pm 0.6$ a.u). Conversely, PSD95 puncta intensity was reduced in CLiCl-treated cultures (control, $6.99 \pm 0.4$; cLiCl: $5.67 \pm 0.2$ a.u.; Fig. $3 \mathrm{E}$ ), in agreement with the reduction of the mean head diameter of mature spines seen in Fig $2 \mathrm{H}$. Puncta density and colocalization of the inhibitory presynaptic vesicular GABA transporter (VGAT) and postsynaptic GABA receptor scaffold Gephyrin were also quantified (Fig. 3A, B). We observed a significant increase in the density of Gephyrin puncta, and VGAT/Gephyrin co-clusters, in CLiCl-treated neurons (control: $7.34 \pm 0.5$; cLiCl: $11.56 \pm 1.4$ Gephyrin puncta/10 $\mathrm{mm}$; control: $1.87 \pm 0.09$; cLiCl: $2.58 \pm 0.2$ of VGAT/Gephyrin coclusters $/ 10 \mu \mathrm{m}$; Fig. 3B). Gephyrin puncta intensity was unchanged but VGAT puncta density was increased in cLiCl-treated neurons (supplementary Fig. 2A, B). The data indicate that lithium treatment increased the number of inhibitory synapses.

To further assess the reduction in number of excitatory synapses (Fig. 3D) induced by $\mathrm{CLiCl}$, and determine whether other synaptic changes are occurring, we measured protein levels of PSD95, GluA1 and GluA2 AMPAR receptor subunits by western blot (Fig. 3F, G). GluA1 protein was unchanged, whereas GluA2 and PSD95 were significantly reduced in response to $\mathrm{CLiCl}(-13.8 \%$ GluA2 and -16.9\% PSD95 of controls; Fig. 3G). This data suggests that cLiCl treatment downregulates GluA2containing AMPA receptors, as well as the number of excitatory synapses. Interestingly, the results were accentuated by a higher dose of $\mathrm{CLiCl}(3.5 \mathrm{mM}$; $-54.42 \% \mathrm{GluA2}$ and $-54.49 \%$ PSD95 of controls; Supplementary Fig. 2D). Notably, the expression level of AMPA receptors and PSD95 were unchanged when neurons were treated acutely (aLiCl,1.5mM) for $4 \mathrm{~h}$ (Supplementary Fig. 2E), suggesting longer time is needed for $\mathrm{LiCl}$ to alter the levels of these proteins. The expression levels of Synapsin 1 and Gephyrin were unchanged by $\mathrm{CLiCl}$ or aLiCl $(1.5 \mathrm{mM}$, Fig. $3 \mathrm{G}$ and Supplementary Fig. 2D, E).

\section{Lithium decreases neuronal excitability and excitatory synaptic transmission, while increasing inhibitory synaptic transmission}

To examine the functional consequence of lithium treatment on neuronal networks, we assessed intrinsic membrane excitability and action potential generation, in addition to quantification of excitatory and inhibitory synaptic transmission. To assess neuronal excitability, we recorded membrane deflection in response to current injection (Supplementary Fig. 3B) and action potential (AP) firing induced by depolarizing currents in current clamp. Although highly variable, cLiCl-treated neurons appeared to fire fewer APs than control neurons (Fig. 4A-C and supplementary Fig. 3A), indicating that $\mathrm{cLiCl}$ reduces cell excitability. We then assayed sodium and potassium currents in voltage clamp and found both were reduced in CLiCl-treated neurons. Specifically, peak sodium current was $-16.3 \%$ of control (Fig. 4D, E; control: $4.97 \pm 0.3 \mathrm{pA} ; \mathrm{CLiCl}: 4.16 \pm 0.3 \mathrm{pA}$ ), and slow and 
fast potassium currents were reduced $-19.3 \%$ and $-12.13 \%$ in $\mathrm{CLiCl}$-treated neurons, compared to controls (Slow K current; control: $2.6 \pm 0.15$ pA; cLiCl: $2.1 \pm 0.13$ pA; Fast K current; control: $3.3 \pm 0.19$ pA; cLiCl: $2.9 \pm 0.16 \mathrm{pA}$; Fig. 4F-H, and supplementary Fig. $3 \mathrm{C}$ ) These data demonstrate that cLiCl treatment alters sodium and potassium channel conductances, and decreases membrane excitability.

Synaptic network activity was assessed by recording quanta of AMPAR-mediated miniature excitatory, and GABAR-mediated miniature inhibitory post-synaptic currents (mEPSCs and mIPSCs) by voltage-clamp recording (Fig. $4 \mathrm{l}, \mathrm{K}$ ). In neurons treated with $\mathrm{CLiCl}$, mEPSC event amplitude was $27 \%$ increased compared to control neurons (control: $29.67 \pm 1.5 \mathrm{pA} ; \quad \mathrm{cLiCl}: 37.71 \pm 1.9 \mathrm{pA}$ ) and event frequency was reduced by $47 \%$ (control: $12.44 \pm 1.4 \mathrm{~Hz}$; cLiCl: $6.5 \pm 1 \mathrm{~Hz}$; Fig. $2 \mathrm{~J}$ and supplementary Fig. 4A, B), while no changes were observed in event decay tau (Fig. 4J). Event amplitude was not different for mIPSCs (control: $23.46 \pm 1.8 \mathrm{pA}$; cLiCl: $24.25 \pm 1.9 \mathrm{pA}$ ), but there was a significant increase in mIPSC event frequency in $\mathrm{CLiCl}$ treated cultures (control: $3.3 \pm 0.35 \mathrm{~Hz}$; cLiCl: $4.8 \pm 0.53$ $\mathrm{Hz}$; Fig. 4L and supplementary Fig. 4D, E), and again no change in event decay tau (Fig. 4I). Measures of membrane properties of voltage-clamp recordings can be found in supplementary Fig 4C, F. Together, electrophysiological experiments demonstrate that $\mathrm{CLiCl}$ treatment alters synaptic network properties by decreasing excitatory and increasing inhibitory activity.

\section{Chronic lithium treatment downregulates mGluR-mediated calcium response and signaling.}

Since $\mathrm{CLiCl}$ treatment downregulated the major depolarizing AMPAR current at glutamatergic synapses, it is of interest to determine which regulatory signal transduction pathways are altered, and whether any changes in these are a consequence, or cause, of altered synaptic transmission. To this end, we investigated ionotropic and metabotropic glutamate receptor-mediated calcium signaling, in cultures acutely or chronically treated with LiCl. Ratiometric calcium imaging was conducted to measure intracellular calcium levels and flux upon stimulation. Tetrodotoxin (TTX) was added to block sodium channels and action potential burst firing, thus calcium flux was directly in response to glutamate receptor activation. The intracellular calcium level at rest was similar between $\mathrm{cLiCl}$ and control-treated neurons (Supplementary Fig. 5A). Control neurons were first exposed to repeated glutamate pulses, which did not attenuate calcium $\left(\mathrm{Ca}^{2+}\right)$ flux upon repeated applications (Supplementary Fig. 5B). Then, following exposure to $1 \mu \mathrm{M}$ glutamate, an acute $(5 \mathrm{~min} 1.5 \mathrm{mM}) \mathrm{LiCl}$ treatment was applied prior to repeated glutamate stimulations. The second calcium response was similar to the first, indicating that $\mathrm{LiCl}$ does not directly reduce glutamate-induced $\mathrm{Ca}^{2+}$ flux or act as an antagonist of glutamate receptors (Fig. 5A). The use of specific agonists of NMDA (Fig. 5B) and mGluR5 (Fig. 5C) shows that acute LiCl treatment had no differential effect on either NMDA or mGluR5-mediated $\mathrm{Ca}^{2+}$ responses (Fig. 5B, C). A medium-term $\mathrm{LiCl}$ treatment for $4 \mathrm{~h}$ similarly did not alter glutamate-induced $\mathrm{Ca}^{2+}$ flux (supplementary Fig $5 \mathrm{C}$ ).

In contrast to acute application, glutamate stimulation of neurons that were chronically treated with $\mathrm{CLiCl}$ (7 days) exhibited a significant decrease in $\mathrm{Ca}^{2+}$ response amplitude (cLiCl: $\Delta \mathrm{F}=73.9 \%$ of control; Fig. 5D). The amplitude of the $\mathrm{Ca}^{2+}$ response upon specific activation of NMDA receptors was unchanged, indicating that chronic $\mathrm{LiCl}$ treatment did not affect NMDAR-mediated $\mathrm{Ca}^{2+}$ responses (Fig. 5E). Conversely, CLiCl treatment significantly reduced $\mathrm{Ca}^{2+}$ response amplitude produced by direct stimulation of mGluR5 (by DHPG agonism; $\mathrm{CLiCl}, \Delta \mathrm{F}=70.8 \%$ of control; Fig. $5 \mathrm{~F}$ ). The data suggest that $\mathrm{CLiCl}$ exposure specifically reduces $\mathrm{Ca}^{2+}$ release from the endoplasmic reticulum (ER). This attenuation of $\mathrm{Ca}^{2+}$ responses to glutamate and DHPG stimulation could be due to impaired receptor activation e.g., a reduction in the number or sensitivity of mGluR5 receptors at the cell surface, or IP3 
receptors on the ER. Alternatively, lithium may affect the mGluR5-PLC-PIP2-DAG-IP3 signaling cascade, i.e. through altered PLC activation, PIP2 hydrolysis or DAG and IP3 availability in the cell. Either possibility would result in reduced ER calcium release.

To determine whether cLiCl-induced attenuation of glutamate-mediated $\mathrm{Ca}^{2+}$ responses affects downstream signaling pathways, we assayed a major downstream target of mGluR5 activation, protein kinase $\mathrm{C}(\mathrm{PKC})$, which is responsible for regulating a wide range of neuronal function, such as excitability, neurotransmission, and plasticity (33-37). PKC $\gamma$ isoform is exclusively expressed in the brain, and its activity is regulated by phosphorylation at threonine 514 (phPKC $\gamma$ ). The levels of phPKC $\gamma$ measured by Western Blot from neurons treated with 2, 5 and $10 \mathrm{mM}$ of $\mathrm{LiCl}$ for 4 here similar to controls (Fig. 5G). However, phPKC $\gamma$ levels, were reduced following $\mathrm{CLiCl}(1.5 \mathrm{mM})$ treatment (a reduction of $21.67 \%$; Fig. $5 \mathrm{G}$ ). Our data demonstrate that PKC $\gamma$ activity is not directly affected by $\mathrm{LiCl}$, but is a consequence of prolonged exposure.

A second major downstream effector of mGluR5 stimulation is GSK3 $\beta$, a kinase involved in several neuronal processes such as cytoskeletal reorganization and neuroplasticity (38). Phosphorylation of GSK3B at the Serine 9 (phGSK3ß) residue inhibits GSK3ß kinase activity. In contrast to acute LiCl effects on PKC, a $4 \mathrm{~h} \mathrm{LiCl}$ treatment with increasing concentrations $(2,5$ and $10 \mathrm{mM})$ and chronic $\mathrm{LiCl}$ treatment both significantly increased phGSK3 $\beta$, in a dose-dependent manner (Fig. $5 \mathrm{H}$ ). These results demonstrate that $\mathrm{LiCl}$ has a rapid, and likely direct, effect on GSK3 $\beta$ kinase activity ( $\mathrm{LiCl} 2 \mathrm{mM}$ : $144 \%$; LiCl 5mM: 147\%; LiCl 10mM: 163\% and cLiCl 1.5mM: 129.5\% of controls). 


\section{DISCUSSION}

Here, we provide the first holistic report of chronic lithium treatment decreasing the balance of excitatory to inhibitory synaptic transmission in cortical neuron networks. This appeared to be a result of altered intracellular calcium signal transduction, expressed by changes to the number and function of excitatory, and inhibitory synaptic connections.

Throughout development and into adulthood, neural connectivity at synapses is subject to dynamic regulation including formation, maintenance, and elimination of synapses themselves. Synaptic transmission is believed to be the means by which all experiences and motivations are stored and utilized, and synaptic plasticity (rapid, activity-dependent alterations to synaptic transmission) is the leading candidate for the cellular basis of learning and memory. In the mammalian forebrain, most excitatory synapses occur on dendritic spines, and changes to their number, morphology, and activity are modelled by increases (long term potentiation; LTP) and decreases (long-term depression; LTD) in synaptic weighting $(39,40)$. With LTP, spines enlarge and become more mushroom-like, whereas LTD is associated with spine shrinkage. Disruptions to dendritic spine shape, size or number accompany many neurodegenerative diseases, and it has been suggested that dendritic spine alterations are also the substrate of many neuropsychiatric disorders, particularly those that involve deficits in information processing, such as autism spectrum disorder and schizophrenia (40).

Decreased spine density has been shown post-mortem in a preliminary study of the subiculum in mood disorder patients (41), and the prefrontal cortex of BD patients (42). It is unclear how reduced spine density in these individuals might reflect a general state of the condition, a brain region-specific effect, or whether it could even be a result of successful medication. In our hands, lithium reduced measures of excitatory spine maturity, and appeared to utilize processes similar to those employed during physiological LTD, decreasing excitatory activity and the number of mature vs. immature spines. The increase of mEPSC amplitude observed here in neurons treated with cLiCl could reflect the increase of immature spines phenotype as suggested in previous studies (43-45).

In support of our results, chronic lithium treatment reduced spine density in a Fragile $X$ mouse model (30). However, spine density was shown to be increased with acute lithium treatment in a DIXDC1 KO mouse model of depression (31). It may be that lithium generally facilitates network rearrangements and normalizes spine dysfunction in whichever direction is required, but further investigations may provide consensus on which direction and over what time-frame changes usually occur. It has also been proposed that lithium rescues spine pathology in BD by reducing phosphorylation of the cytoskeleton regulator collapsing response mediator protein-2 (CRPM2) (32), in rat hippocampal cultures, chronic treatment with a dose $2 x$ higher than here, resulted in enlarged spines and increased spine density. Here, we found that chronic lithium not only reduced spine number, but also decreased the percentage of mature spines, mature spine width, and PSD95 puncta intensity. These discrepancies may be due to the higher dose and/or different responses between rat hippocampus and mouse cortex. More studies will be required to settle this discrepancy.

Several rodent models of mania have been generated which traditionally relied upon pharmacological (e.g., psychostimulant amphetamine-induced) or environmental (sleep deprivationinduced) stresses to induce mania-like states, and more recently several transgenic mice have been developed $(46,47)$. A recent study using knock-in mice of the Ank3 W1989R (48), a variant reported as carried by a BD family (and found in approximately 1:10,000 European Americans) (49), showed a reduction in $\mathrm{mIPSCS}$ and an increase in $\mathrm{mEPSC}$ frequency, leading to neuronal hyperexcitability. If this is the case in untreated lithium-responsive patients, then our finding that chronic lithium treatment 
has the opposite effect may explain its therapeutic effect. This could also explain the efficacy of lithium in BD Ank3 mutation carriers(48). Elsewhere, Yang el al (50) generated forebrain-specific PLC 1 knock-out mice that exhibited manic-like behavior and cognitive deficits associated with a significant reduction in mIPSC frequency. Here, we show that chronic lithium treatment promotes inhibitory transmission, and increases gephyrin clusters at inhibitory synapses. Together, these studies suggest that manic phases correspond to an increased E/I synaptic ratio. Our results are in line with other studies $(51,52)$ indicating that chronic lithium treatment can counteract abnormalities in E/I circuit balance observed in the mania state of BD animal models, by rearranging the number, morphology and function of excitatory and inhibitory synapses, in a manner that favours inhibition. On this note, elsewhere, lithium has also been shown to reduce synaptic AMPA receptor expression (53-55), again consistent with the reduction in excitatory synapse number observed here.

An important aspect of our results is the demonstration that chronic effects of lithium are distinct from acute effects. Specifically, lithium treatment from $5 \mathrm{~min}$ to $4 \mathrm{~h}$ did not affect glutamate-mediated $\mathrm{Ca}^{2+}$ responses, demonstrating that lithium did not act as an antagonist of glutamate receptor transmission in our hands. Conversely, mGluR5 glutamate receptor-mediated $\mathrm{Ca}^{2+}$ signaling was specifically reduced in neurons chronically treated with $\mathrm{LiCl}$, suggesting that time is required for lithium to attenuate the mGluR5-PIP2-IP3 pathway. Sourial-Bassilious et al (56) concluded lithium attenuates intracellular $\mathrm{Ca}^{2+}$ levels due to the downregulation of mGluR5 expression at the plasma membrane, as well as a decrease in intracellular $\mathrm{Ca}^{2+}$ in the ER. Others have suggested lithium inhibits inositol monophosphatase and inositol polyphosphate-1-phosphatase, in addition to the inositol transporter (57). This would reduce PIP2 and IP3 availability in the cell to trigger $\mathrm{Ca}^{2+}$ release from the ER. Either way, we sought to find out whether a decrease in $\mathrm{Ca}^{2+}$ signaling caused by chronic lithium treatment altered downstream effectors.

Our results demonstrate that chronic and acute lithium inhibit GSK3 $\beta$ kinase activity, in a dose dependent manner, but only chronic treatment reduces PKC $\gamma$ kinase activity. These two kinases are major regulators of synaptic receptor traffic and function (58), actin cytoskeleton reorganization, neuronal transmission and plasticity, as well as gene expression $(37,38,59-61)$. This may be the primary mechanism by which lithium acts to prevent mania in $B D$, where the glutamatergic system is predicted to be overactivated (22-24) and the inhibitory system downregulated $(62,63)$. On this background, increased PKC activity and levels have been found post-mortem in the frontal cortex of bipolar patients. Furthermore, PKC hyperactivity has been detected in the blood of BD patients (64) and animal models of mania, in agreement with our conclusions here and in support of the potential for PKC inhibitors as therapeutics for mania in $\operatorname{BD}(59,65-67)$. It has been previously shown that lithium can reduce glutamatergic neurotransmission by slowing synaptic vesicle (SV) exocytosis (68). This may explain increased VGlut1 cluster intensity we saw here (Supplementary Fig. 2b, c). Although evidence is lacking for how lithium might alter the kinetics of the SV cycle, we would expect reduced GSK3 and PKC activity to impact presynaptic function. It may also be that intracellular $\mathrm{Ca}^{2+}$ signaling, via presynaptic mGluR5 autoreceptors (69) is reduced, which may impair vesicular release (70).

Recent advances in human induced pluripotent stem cell (iPSC) technology have provided the means by which to study an individual patient's neurons. Recently, Mertens et al (71) discovered hyperexcitability in iPSC-derived hippocampal-like neurons from BD patients, which was reversed by lithium treatment (in cells from BD lithium responders). These tools will facilitate our future studies of lithium's mode of action, at the cellular and network level, in neurons from BD lithium responders 
All the authors declare no conflict of interest. benefit of lithium, but with less side-effects.

\section{ACKNOWLEDGMENTS} the Vanier Canada Graduate Scholarship from the CIHR.

\section{AUTHOR CONTRIBUTIONS} edited by A.J.M.

vs non-responders. We will also determine whether the working model we provide here operates in human scenarios. Ongoing efforts will examine the mGluR5-PLC-IP3 intracellular $\mathrm{Ca}^{2+}$ signaling pathway in neurons from BD lithium responders, and the effects of lithium treatment. We hope this will facilitate development of novel disease-modifying therapies for $\mathrm{BD}$, with the same therapeutic

We gratefully acknowledge the financial supports from Fonds de recherche en santé du Québec (FRSQ), Ellen foundation and Killam to A.J.M, the Canadian Institutes of Health Research (CIHR) grant (\#332971 to G.A.R), ERA PerMed grant to MA and G.A.R, the Healthy Brains for Healthy Lives (HBHL) and Bettencourt-Schueller fondation grants to BC and the RI-MUHC 2020 fellowship to LS. We also thank the microscopy platform of the Montreal Neurological Institute (MNI) and the Molecular Tools Platform of the CERVO Brain Research Center for providing us the AAV constructs. We would also like to thank the animal care facility of MNI and Bruno Vieira for assistance with mice handling. We also thank Dr Simon Wing lab for the kind gift of reagents. G.A.R. holds a Canada Research Chair in Genetics of the Nervous System and the Wilder Penfield Chair in Neurosciences. C.L. is a recipient of

AK performed all the spine morphology, density and excitatory/inhibitory synapses analyses. AK, AKam and NK performed the electrophysiological recordings, analyzed by AK. A.R.A performed and analyzed the calcium imaging experiments. $\mathrm{CL}$ analyzed the RNA sequencing. LS performed the cell viability test and provided some computational tools to analyze imaging data. AK prepared all neuronal cultures and all biochemical experiments. AK, A.J.M and G.A.R contributed to study design, curation and development, and data interpretation. A.J.M and G.A.R provided the overall supervision and funding. AK wrote the original draft and all authors revised and commented on the manuscript, 


\section{REFERENCES}

1. Angst J. The emerging epidemiology of hypomania and bipolar II disorder. Journal of affective disorders. 1998;50(2-3):143-51.

2. Moreira ALR, Van Meter A, Genzlinger J, Youngstrom EA. Review and Meta-Analysis of Epidemiologic Studies of Adult Bipolar Disorder. The Journal of clinical psychiatry. 2017;78(9):e1259e69.

3. Vieta E, Berk M, Schulze TG, Carvalho AF, Suppes T, Calabrese JR, et al. Bipolar disorders. Nat Rev Dis Primers. 2018;4:18008.

4. Forstner AJ, Hofmann A, Maaser A, Sumer S, Khudayberdiev S, Muhleisen TW, et al. Genomewide analysis implicates microRNAs and their target genes in the development of bipolar disorder. Translational psychiatry. 2015;5:e678.

5. Perlis RH, Smoller JW, Ferreira MA, McQuillin A, Bass N, Lawrence J, et al. A genomewide association study of response to lithium for prevention of recurrence in bipolar disorder. The American journal of psychiatry. 2009;166(6):718-25.

6. Stahl EA, Breen G, Forstner AJ, McQuillin A, Ripke S, Trubetskoy V, et al. Genome-wide association study identifies 30 loci associated with bipolar disorder. Nat Genet. 2019;51(5):793-803.

7. Cipriani A, Hawton K, Stockton S, Geddes JR. Lithium in the prevention of suicide in mood disorders: updated systematic review and meta-analysis. BMJ (Clinical research ed). 2013;346:f3646.

8. Gitlin M. Lithium side effects and toxicity: prevalence and management strategies. Int J Bipolar Disord. 2016;4(1):27-.

9. Hayes JF, Marston L, Walters K, Geddes JR, King M, Osborn DP. Lithium vs. valproate vs. olanzapine vs. quetiapine as maintenance monotherapy for bipolar disorder: a population-based UK cohort study using electronic health records. World psychiatry : official journal of the World Psychiatric Association (WPA). 2016;15(1):53-8.

10. Miura T, Noma H, Furukawa TA, Mitsuyasu H, Tanaka S, Stockton S, et al. Comparative efficacy and tolerability of pharmacological treatments in the maintenance treatment of bipolar disorder: a systematic review and network meta-analysis. The lancet Psychiatry. 2014;1(5):351-9.

11. Rybakowski JK. Response to lithium in bipolar disorder: clinical and genetic findings. ACS chemical neuroscience. 2014;5(6):413-21.

12. Rybakowski JK, Chlopocka-Wozniak M, Suwalska A. The prophylactic effect of long-term lithium administration in bipolar patients entering treatment in the 1970s and 1980s. Bipolar disorders. 2001;3(2):63-7.

13. Anand A, Nakamura K, Spielberg JM, Cha J, Karne H, Hu B. Integrative analysis of lithium treatment associated effects on brain structure and peripheral gene expression reveals novel molecular insights into mechanism of action. Translational psychiatry. 2020;10(1):103.

14. Malhi GS, Tanious M, Das P, Coulston CM, Berk M. Potential mechanisms of action of lithium in bipolar disorder. Current understanding. CNS drugs. 2013;27(2):135-53.

15. Hokin LE, Dixon JF, Los GV. A novel action of lithium: stimulation of glutamate release and inositol 1,4,5 trisphosphate accumulation via activation of the $\mathrm{N}$-methyl $\mathrm{D}$-aspartate receptor in monkey and mouse cerebral cortex slices. Advances in enzyme regulation. 1996;36:229-44.

16. Dixon JF, Hokin LE. Lithium acutely inhibits and chronically up-regulates and stabilizes glutamate uptake by presynaptic nerve endings in mouse cerebral cortex. Proceedings of the National Academy of Sciences. 1998;95(14):8363.

17. Nonaka S, Hough CJ, Chuang DM. Chronic lithium treatment robustly protects neurons in the central nervous system against excitotoxicity by inhibiting $\mathrm{N}$-methyl-D-aspartate receptor-mediated calcium influx. Proc Natl Acad Sci U S A. 1998;95(5):2642-7.

18. Alda M. Lithium in the treatment of bipolar disorder: pharmacology and pharmacogenetics. Molecular psychiatry. 2015;20(6):661-70.

19. Lenox RH, Wang L. Molecular basis of lithium action: integration of lithium-responsive signaling and gene expression networks. 
20. Turecki G, Grof P, Grof E, D'Souza V, Lebuis L, Marineau C, et al. Mapping susceptibility genes for bipolar disorder: a pharmacogenetic approach based on excellent response to lithium. Molecular psychiatry. 2001;6(5):570-8.

21. Seelan RS, Khalyfa A, Lakshmanan J, Casanova MF, Parthasarathy RN. Deciphering the lithium transcriptome: microarray profiling of lithium-modulated gene expression in human neuronal cells. Neuroscience. 2008;151(4):1184-97.

22. Michael N, Erfurth A, Ohrmann P, Gossling M, Arolt V, Heindel W, et al. Acute mania is accompanied by elevated glutamate/glutamine levels within the left dorsolateral prefrontal cortex. Psychopharmacology. 2003;168(3):344-6.

23. Ongür $D$, Jensen JE, Prescot AP, Stork C, Lundy $M$, Cohen $B M$, et al. Abnormal glutamatergic neurotransmission and neuronal-glial interactions in acute mania. Biological psychiatry. 2008;64(8):718-26.

24. Ng WX, Lau IY, Graham S, Sim K. Neurobiological evidence for thalamic, hippocampal and related glutamatergic abnormalities in bipolar disorder: a review and synthesis. Neuroscience and biobehavioral reviews. 2009;33(3):336-54.

25. Khayachi A, Gwizdek C, Poupon G, Alcor D, Chafai M, Casse F, et al. Sumoylation regulates FMRP-mediated dendritic spine elimination and maturation. Nat Commun. 2018;9(1):757.

26. Hedya SA, Avula A, Swoboda HD. Lithium Toxicity. StatPearls. Treasure Island (FL): StatPearls Publishing

StatPearls Publishing LLC.; 2020.

27. Papa M, Bundman MC, Greenberger V, Segal M. Morphological analysis of dendritic spine development in primary cultures of hippocampal neurons. J Neurosci. 1995;15(1 Pt 1):1-11.

28. Boyer C, Schikorski T, Stevens CF. Comparison of Hippocampal Dendritic Spines in Culture and in Brain. The Journal of Neuroscience. 1998;18(14):5294.

29. Takahashi H, Sekino Y, Tanaka S, Mizui T, Kishi S, Shirao T. Drebrin-dependent actin clustering in dendritic filopodia governs synaptic targeting of postsynaptic density-95 and dendritic spine morphogenesis. J Neurosci. 2003;23(16):6586-95.

30. Liu ZH, Chuang DM, Smith CB. Lithium ameliorates phenotypic deficits in a mouse model of fragile $X$ syndrome. The international journal of neuropsychopharmacology. 2011;14(5):618-30.

31. Martin PM, Stanley RE, Ross AP, Freitas AE, Moyer CE, Brumback AC, et al. DIXDC1 contributes to psychiatric susceptibility by regulating dendritic spine and glutamatergic synapse density via GSK3 and Wnt/beta-catenin signaling. Molecular psychiatry. 2018;23(2):467-75.

32. Tobe BTD, Crain AM, Winquist AM, Calabrese B, Makihara H, Zhao WN, et al. Probing the lithium-response pathway in hiPSCs implicates the phosphoregulatory set-point for a cytoskeletal modulator in bipolar pathogenesis. Proc Natl Acad Sci U S A. 2017;114(22):E4462-e71.

33. Saito N, Shirai Y. Protein kinase C gamma (PKC gamma): function of neuron specific isotype. Journal of biochemistry. 2002;132(5):683-7.

34. Callender Julia A, Newton Alexandra C. Conventional protein kinase $C$ in the brain: 40 years later. Neuronal Signaling. 2017;1(2).

35. Saxena A, Scaini G, Bavaresco DV, Leite C, Valvassoria SS, Carvalho AF, et al. Role of Protein Kinase $C$ in Bipolar Disorder: A Review of the Current Literature. Molecular Neuropsychiatry. 2017;3(2):108-24.

36. Freeley $\mathrm{M}$, Kelleher $\mathrm{D}$, Long $\mathrm{A}$. Regulation of Protein Kinase $\mathrm{C}$ function by phosphorylation on conserved and non-conserved sites. Cellular signaling. 2011;23(5):753-62.

37. Sossin WS. Isoform specificity of protein kinase Cs in synaptic plasticity. Learning \& memory (Cold Spring Harbor, NY). 2007;14(4):236-46.

38. Salcedo-Tello P, Ortiz-Matamoros A, Arias C. GSK3 Function in the Brain during Development, Neuronal Plasticity, and Neurodegeneration. Int J Alzheimers Dis. 2011;2011:189728-.

39. Bliss TV, Collingridge GL. A synaptic model of memory: long-term potentiation in the hippocampus. Nature. 1993;361(6407):31-9. 
40. Penzes $P$, Cahill ME, Jones KA, VanLeeuwen JE, Woolfrey KM. Dendritic spine pathology in neuropsychiatric disorders. Nat Neurosci. 2011;14(3):285-93.

41. Rosoklija G, Toomayan G, Ellis SP, Keilp J, Mann JJ, Latov N, et al. Structural abnormalities of subicular dendrites in subjects with schizophrenia and mood disorders: preliminary findings. Archives of general psychiatry. 2000;57(4):349-56.

42. Konopaske GT, Lange N, Coyle JT, Benes FM. Prefrontal cortical dendritic spine pathology in schizophrenia and bipolar disorder. JAMA psychiatry. 2014;71(12):1323-31.

43. Segal $M$, Greenberger V, Korkotian E. Formation of dendritic spines in cultured striatal neurons depends on excitatory afferent activity. 2003;17(12):2573-85.

44. Segal M. Dendritic spines, synaptic plasticity and neuronal survival: activity shapes dendritic spines to enhance neuronal viability. 2010;31(12):2178-84.

45. Segal M. Dendritic spines and long-term plasticity. Nature Reviews Neuroscience. 2005;6(4):277-84.

46. Logan RW, McClung CA. Animal models of bipolar mania: The past, present and future. Neuroscience. 2016;321:163-88.

47. Lee $Y$, Zhang $Y$, Kim S, Han K. Excitatory and inhibitory synaptic dysfunction in mania: an emerging hypothesis from animal model studies. Experimental \& molecular medicine. 2018;50(4):12.

48. Nelson AD, Caballero-Floran RN, Rodriguez Diaz JC, Hull JM, Yuan Y, Li J, et al. Ankyrin-G regulates forebrain connectivity and network synchronization via interaction with GABARAP. Molecular psychiatry. 2018.

49. Lek M, Karczewski KJ, Minikel EV, Samocha KE, Banks E, Fennell T, et al. Analysis of proteincoding genetic variation in 60,706 humans. Nature. 2016;536(7616):285-91.

50. Yang YR, Jung JH, Kim SJ, Hamada K, Suzuki A, Kim HJ, et al. Forebrain-specific ablation of phospholipase Cgamma1 causes manic-like behavior. Molecular psychiatry. 2017;22(10):1473-82.

51. Motohashi N, Ikawa K, Kariya T. GABAB receptors are up-regulated by chronic treatment with lithium or carbamazepine. GABA hypothesis of affective disorders? European journal of pharmacology. 1989;166(1):95-9.

52. Tyagarajan SK, Ghosh H, Yevenes GE, Nikonenko I, Ebeling C, Schwerdel C, et al. Regulation of GABAergic synapse formation and plasticity by GSK3beta-dependent phosphorylation of gephyrin. Proc Natl Acad Sci U S A. 2011;108(1):379-84.

53. Du J, Creson TK, Wu L-J, Ren M, Gray NA, Falke C, et al. The role of hippocampal GluR1 and GluR2 receptors in manic-like behavior. J Neurosci. 2008;28(1):68-79.

54. Du J, Gray NA, Falke CA, Chen W, Yuan P, Szabo ST, et al. Modulation of synaptic plasticity by antimanic agents: the role of AMPA glutamate receptor subunit 1 synaptic expression. J Neurosci. 2004;24(29):6578-89.

55. Gray NA, Du J, Falke CS, Yuan P, Manji HK. Lithium regulates total and synaptic expression of the AMPA glutamate receptor GluR2 in vitro and in vivo. Annals of the New York Academy of Sciences. 2003;1003:402-4.

56. Sourial-Bassillious N, Rydelius PA, Aperia A, Aizman O. Glutamate-mediated calcium signaling: a potential target for lithium action. Neuroscience. 2009;161(4):1126-34.

57. Harwood AJ. Lithium and bipolar mood disorder: the inositol-depletion hypothesis revisited. Molecular psychiatry. 2005;10(1):117-26.

58. Wei J, Liu W, Yan Z. Regulation of AMPA receptor trafficking and function by glycogen synthase kinase 3. J Biol Chem. 2010;285(34):26369-76.

59. Abrial E, Lucas $G$, Scarna $H$, Haddjeri N, Lambas-Senas L. A role for the PKC signaling system in the pathophysiology and treatment of mood disorders: involvement of a functional imbalance? Molecular neurobiology. 2011;44(3):407-19.

60. Jaworski T, Banach-Kasper E, Gralec K. GSK-3beta at the Intersection of Neuronal Plasticity and Neurodegeneration. Neural Plast. 2019;2019:4209475.

61. Lee H-K. Synaptic plasticity and phosphorylation. Pharmacol Ther. 2006;112(3):810-32. 
62. Brambilla P, Perez J, Barale F, Schettini G, Soares JC. GABAergic dysfunction in mood disorders. Molecular psychiatry. 2003;8(8):721-37, 15.

63. Ruiz-Veguilla M, Martin-Rodriguez JF, Palomar FJ, Porcacchia P, Alvarez de Toledo P, PeronaGarcelan S, et al. Trait- and state-dependent cortical inhibitory deficits in bipolar disorder. Bipolar disorders. 2016;18(3):261-71.

64. Hahn CG, Friedman E. Abnormalities in protein kinase $C$ signaling and the pathophysiology of bipolar disorder. Bipolar disorders. 1999;1(2):81-6.

65. Szabo ST, Machado-Vieira R, Yuan P, Wang Y, Wei Y, Falke C, et al. Glutamate receptors as targets of protein kinase $C$ in the pathophysiology and treatment of animal models of Mania. Neuropharmacology. 2009;56(1):47-55.

66. Einat H, Yuan P, Szabo ST, Dogra S, Manji HK. Protein Kinase C Inhibition by Tamoxifen Antagonizes Manic-Like Behavior in Rats: Implications for the Development of Novel Therapeutics for Bipolar Disorder. Neuropsychobiology. 2007;55(3-4):123-31. Inhibition Rescues Manic-Like Behaviors and Hippocampal Cell Proliferation Deficits in the Sleep Deprivation Model of Mania. International Journal of Neuropsychopharmacology. 2015;18(2).

68. Tang W, Cory B, Lim KL, Fivaz M. The mood stabilizer lithium slows down synaptic vesicle cycling at glutamatergic synapses. bioRxiv. 2019:780866.

69. Musante V, Neri E, Feligioni M, Puliti A, Pedrazzi M, Conti V, et al. Presynaptic mGlu1 and mGlu5 autoreceptors facilitate glutamate exocytosis from mouse cortical nerve endings. Neuropharmacology. 2008;55(4):474-82.

600 70. Pittaluga A. Presynaptic Release-Regulating mGlu1 Receptors in Central Nervous System. Front Pharmacol. 2016;7:295-. hyperexcitable neurons from patients with bipolar disorder. Nature. 2015;527(7576):95-9.

605

606

72 Nunes A, Stone W, Ardau R, Berghöfer A, Bocchetta A, Chillotti C, et al. Exemplar Scoring Identifies Genetically Separable Phenotypes of Lithium Responsive Bipolar Disorder. Our unpublished data. 
Figure 1: Chronic lithium treatment alters gene expression in mouse cortical neurons.

A) Gene clustering of differentially expressed genes of primary cortical mouse neurons at 18 DIV treated chronically with $\mathrm{LiCl}(1.5 \mathrm{mM})$ for 7 days compared to controls. Each gene cluster is identified by a color. B) Significant pathways of gene clusters identified through gene network analysis for lithium treatment effect on primary cortical mouse neurons.

Figure 2: Chronic lithium treatment leads to changes in spine morphology.

A) Representative confocal image of dendrites expressing free GFP, bar $10 \mu \mathrm{m}$. B) enlargement of a dendrite expressing free GFP treated or not with $\mathrm{LiCl}(1.5 \mathrm{mM})$ for 7 days, bar $10 \mu \mathrm{m}$. C) Cell viability test shows no toxic effect of $\mathrm{LiCl}(1.5 \mathrm{mM})$ on neurons treated for 7 days, from 5 independent experiments. Scatter plots show the density of protrusions (D) and the relative proportion of mushroom spines (E) stubby spines (F) and thin spines (G) treated or not with LiCl for 7 days. H) Scatter plots show the spine head mushroom diameter from neurons treated or not by LiCl. Data shown in $\mathbf{C}-\mathbf{H}$ are the mean \pm s.e.m. and statistical significance determined by parametric unpaired $\mathrm{t}$ test for $\mathbf{C}-\mathbf{G}$ and non-parametric Mann-Whitney test for $\mathbf{H}$. $\mathbf{N}=\sim 5000$ protrusions per condition from $\sim 45$ neurons from four independent experiments, ${ }^{* * *} p<0.0005,{ }^{* *} p=0.0013$.

Figure 3: Chronic lithium treatment induces excitatory and inhibitory synaptic changes.

A) Representative confocal image of dendrites expressing free GFP from neurons treated or not with $\mathrm{LiCl}(1.5 \mathrm{mM})$ for 7 days, with antibodies directed against Vgat and Gephyrin. Arrowheads show the Vgat and Gephyrin puncta localization and the co-localization between Vgat and Gephyrin in the

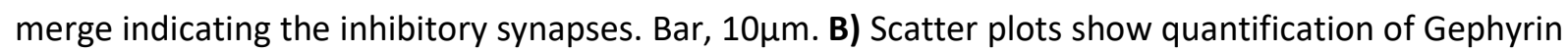
puncta density/10 $\mu \mathrm{m}$ and Vgat-Gephyrin co-cluster density representing the density of inhibitory synapses per $10 \mu \mathrm{m}$ from secondary/tertiary dendrites from neurons treated or not with $\mathrm{LiCl}(1.5 \mathrm{mM})$ for 7 days. $N=32$ neurons per condition from three separate experiments. $\mathrm{LiCl}(1.5 \mathrm{mM})$ for 7 days, with antibodies directed against Vglut1 and PSD95. Arrowheads show the Vglut1 and PSD95 puncta localization and the co-localization between Vglut1 and PSD95 in the merge indicating the excitatory synapses. Bar, $5 \mu \mathrm{m}$. D) Scatter plots show quantification of PSD95 puncta density/10 $\mu \mathrm{m}$ and Vglut1-PSD95 co-cluster density representing the density of excitatory synapses per $10 \mu \mathrm{m}$ from secondary/tertiary dendrites as well as PSD95 puncta intensity $\mathbf{E}$ from neurons treated or not with $\mathrm{LiCl}(1.5 \mathrm{mM})$ for 7 days. $\mathrm{N}=30$ neurons per condition from three separate experiments. Data shown in B-E are the mean \pm s.e.m. and statistical significance was determined using a non-parametric Mann-Whitney test. neuronal extract from neurons treated chronically or not with $\mathrm{LiCl}(1.5 \mathrm{mM})$. G) Quantification with scatter plot of some presynaptic and postsynaptic protein expression levels normalized with GAPDH and represented as percentage of control of 18 DIV neuronal extract from neurons treated chronically or not with $\mathrm{LiCl}(1.5 \mathrm{mM})$ from three to seven separate experiments. Data show the mean \pm s.e.m and statistical significance was determined using one sample $t$ test with hypothetical value 100 for control. 
Figure 4: Chronic lithium treatment reduces neuronal excitability and excitatory transmission, while increasing inhibitory synaptic transmission.

Representative action potential trains in control (A) and chronically $\mathrm{LiCl}(1.5 \mathrm{mM})$ treated neurons (B) at DIV 18, in response to a 1 second depolarizing 120 pA current step from $-65 \mathrm{mV}$. C) Frequencycurrent $(\mathrm{F}-\mathrm{I})$ plot among repetitively-firing neurons. Frequency represents the mean number of spikes/second from 32 neurons per condition from four independent experiments.

Voltage dependence of the amplitude of the sodium current in $\mathbf{D}$ and quantification of the peak amplitude of sodium currents in neurons treated or not chronically with $\mathrm{LiCl}(1.5 \mathrm{mM})$ in E. Voltage dependence of the amplitude of the slow potassium current in $\mathbf{F}$ and quantifications of the peak amplitude of the slow and fast potassium currents in neurons treated or not chronically with LiCl $(1.5 \mathrm{mM})$ in $\mathbf{G}$ and $\mathbf{H}$. The data from $\mathbf{D}-\mathbf{H}$ are from five separate experiments and show the mean \pm s.e.m and statistical significance was determined by a non-parametric Mann-Whitney test. I) Representative sample traces of mEPSCs from neurons treated or not with $\mathrm{LiCl}(1.5 \mathrm{mM})$ for 7 days. Scale bar showed as inset. J) Scatter plot show quantification of amplitude, frequency and decay tau of mEPSCs of $\sim 45$ neurons from four independent experiments. K) Representative sample traces of mIPSCs from neurons treated or not with $\mathrm{LiCl}(1.5 \mathrm{mM})$ for 7 days. Scale bar showed as inset. L) Scatter plot show quantification of amplitude, frequency and decay tau of mIPSCs of $\sim 26$ neurons from three independent experiments. Data shown in $\mathbf{J}$ and $\mathbf{L}$ are the mean \pm s.e.m. and statistical significance determined by non-parametric Mann-Whitney test.

Figure 5: Chronic lithium treatment reduces mGluR-mediated calcium response and signaling. A-C) Representative sample traces of calcium responses after glutamate $(1 \mu \mathrm{M})$, NMDA $(10 \mu \mathrm{M})$ and DHPG $(100 \mu \mathrm{M})$ stimulation with histograms showing the quantification of calcium changes upon stimulation in mouse primary cortical neurons. The second stimulations are preceded by acute LiCl $(1.5 \mathrm{mM})$ treatment of $5 \mathrm{~min}$, then followed by $2 \mathrm{sec}$ of $\mathrm{KCl}$ stimulation. D-F) Representative sample traces of calcium responses after glutamate $(1 \mu \mathrm{M})$, NMDA $(10 \mu \mathrm{M})$ and DHPG $(100 \mu \mathrm{M})$ stimulation with histograms showing the quantification of calcium changes as percentage of control upon drugs stimulations in mouse primary cortical neurons chronically treated or not with $\mathrm{LiCl}(1.5 \mathrm{mM})$ for 7 days. Number of neurons is indicated on each histogram from 3 independent experiments. Data shown in A-F are the mean \pm s.e.m. and statistical significance determined by paired t-test for acute treatment (A-C) and unpaired t-test for chronic treatment (D-F).

G-H) Representative immunoblots and quantification of anti-phosphorylated levels of PKC $\gamma$ (Thr514) and GSK-3 $\beta$ (Ser9) normalized with GAPDH and represented as percentage of control from neuronal extract from mouse primary cortical neurons treated with 2,5 and $10 \mathrm{mM}$ of LiCl for $4 \mathrm{~h}$, or chronically by $\mathrm{LiCl}(1.5 \mathrm{mM})$ for 7 days. The data are from four (for phPKC) and six (for phGSK3) separate experiments and show the mean \pm s.e.m. and statistical significance determined by one sample t-test with hypothetical value 100 for control. 
bioRxiv preprint doi: https://doi.org/10.1101/2020.09.18.303578; this version posted September 19, 2020. The copyright holder for this preprint (which was not certified by peer review) is the author/funder, who has granted bioRxiv a license to display the preprint in perpetuity. It is made available under aCC-BY-NC-ND 4.0 International license.

A

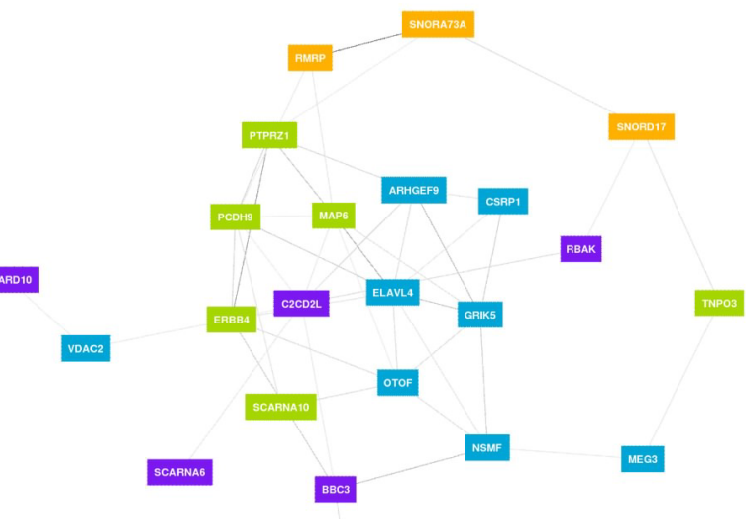

B

\begin{tabular}{l|l} 
Pathway & $\mathbf{P}$ \\
\hline Trafficking of AMPA receptors & 0.000096800 \\
\hline Glutamate binding, activation of AMPA receptors and synaptic activity & 0.000096800 \\
\hline Calcium ion binding & 0.000490000 \\
\hline CREB phosphorylation through the activation of CamkII & 0.000246660 \\
\hline Ras activation upon Ca2+ influx through NMDA receptor & 0.000284473 \\
\hline tRNA processing in the nucleus & 0.000730176 \\
\hline SUMOylation of DNA replication proteins & 0.000929913 \\
\hline COPI-independent Golgi-to-ER retrograde traffic & 0.000990993 \\
\hline Transmission across Chemical Synapses & 0.001112485
\end{tabular}


bioRxiv preprint doi: https://doi.org/10.1101/2020.09.18.303578; this version posted September 19, 2020. The copyright holder for this

preprint (which was not certified by peer review) is the author/funder, who has granted bioRxiv a license to display the preprint in perpetuity. It is made available under aCC-BY-NC-ND 4.0 International license.

A

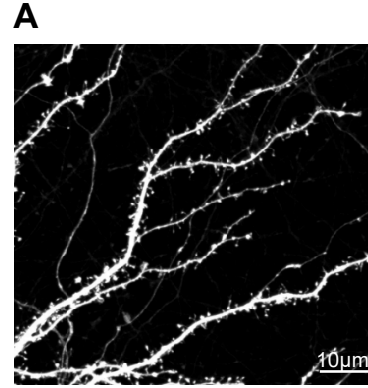

C

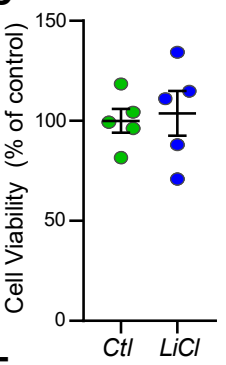

$\mathbf{F}$

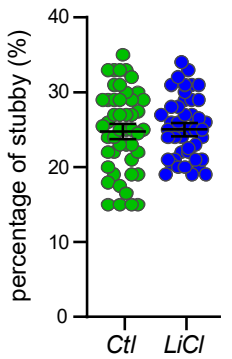

D

G
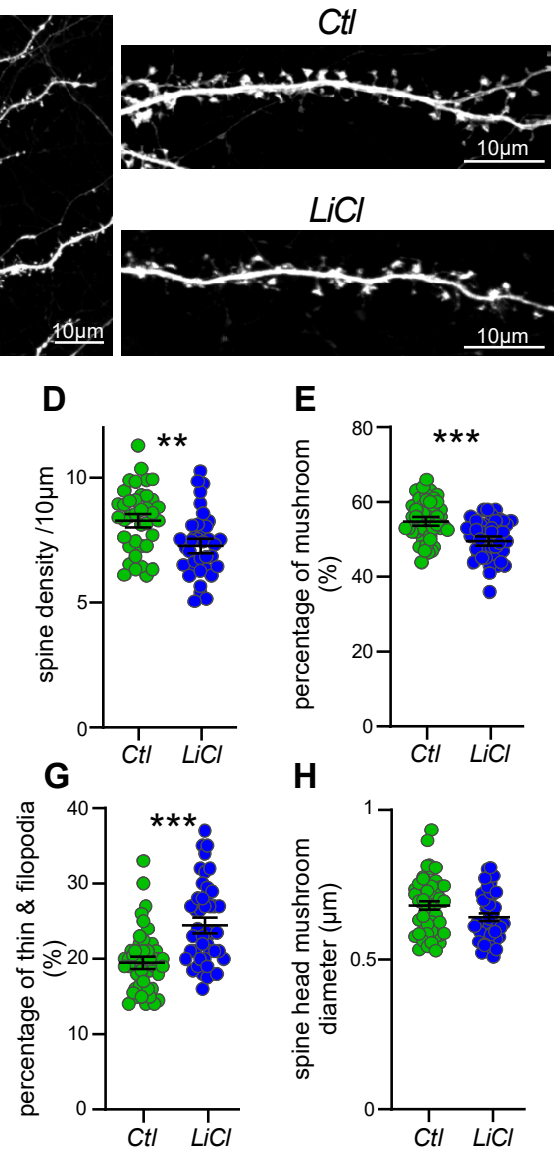

E

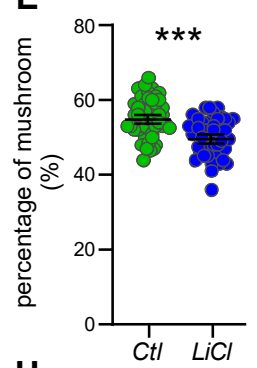

$\mathbf{H}$

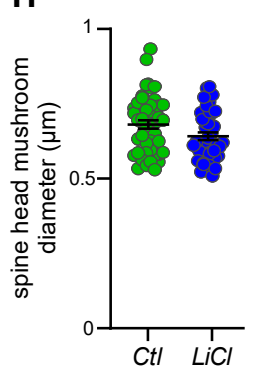



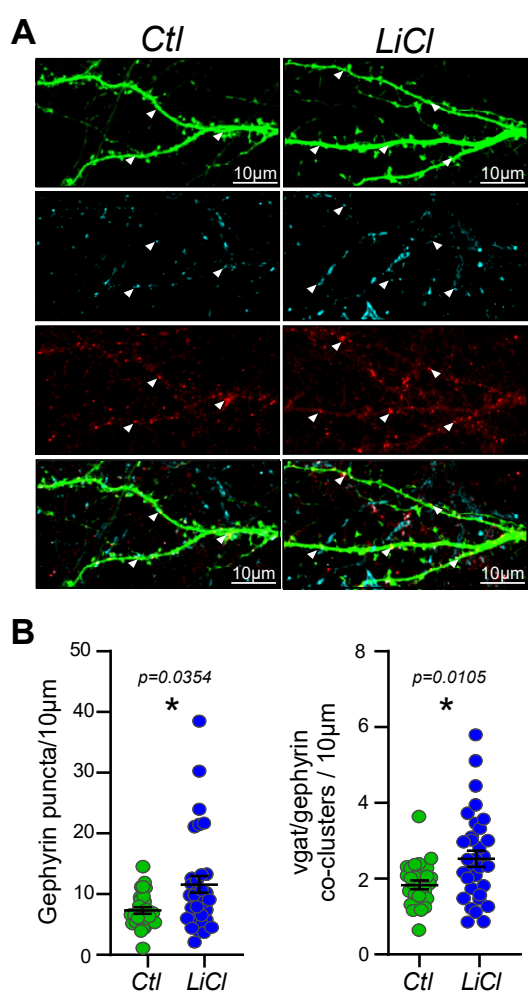

E
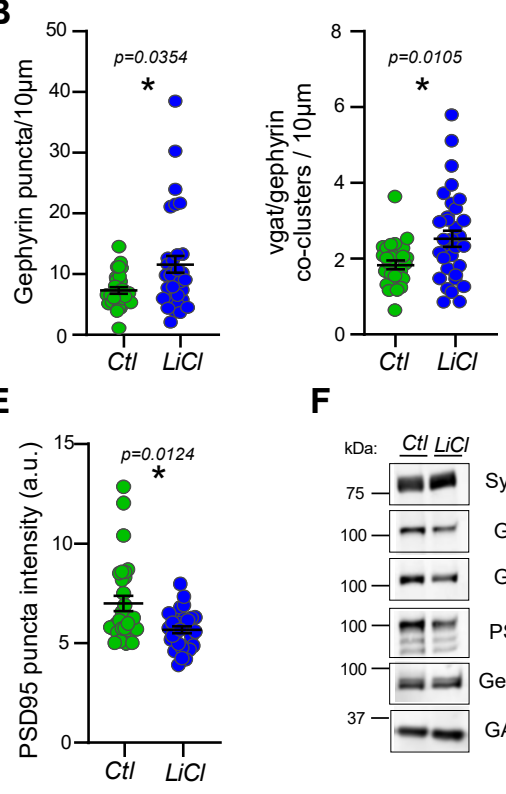

F
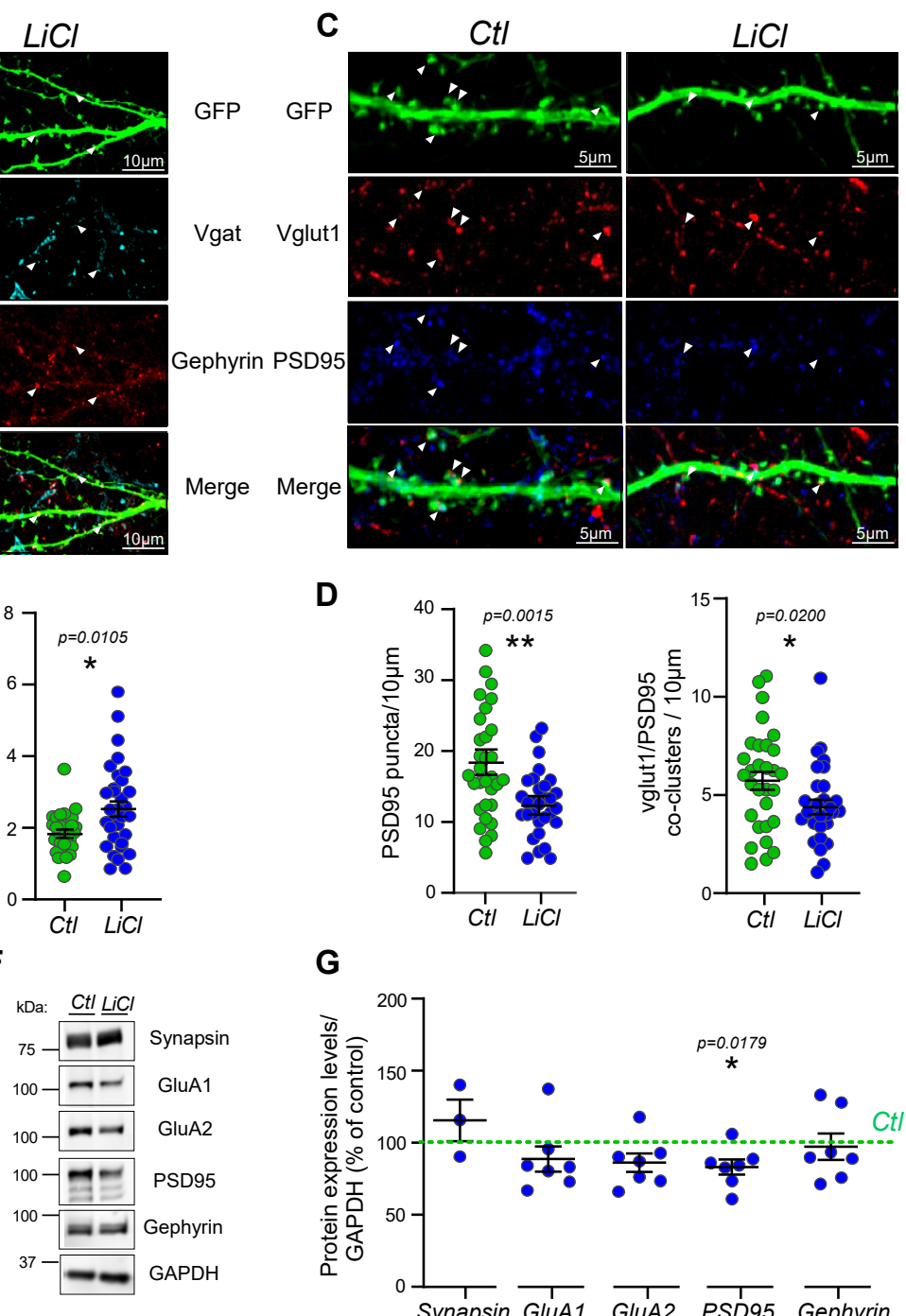

D
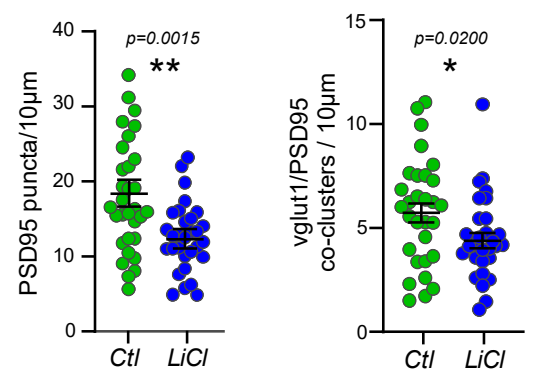

G

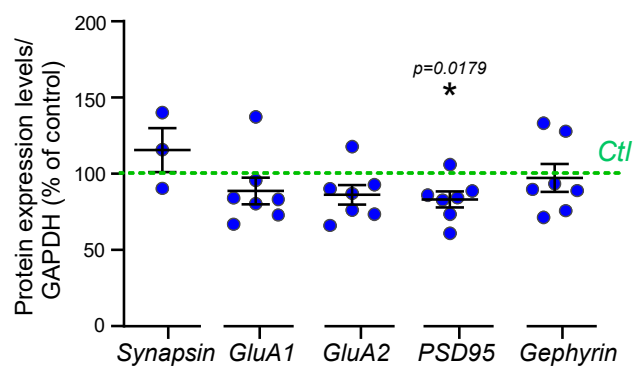


A

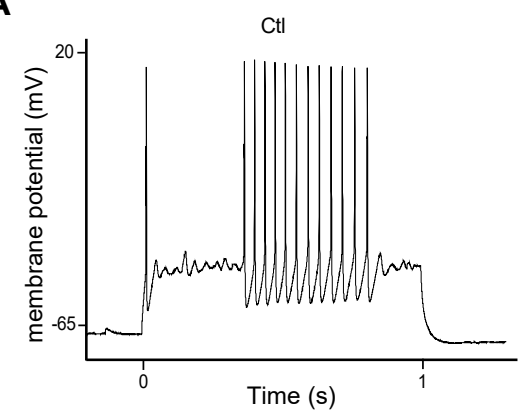

D

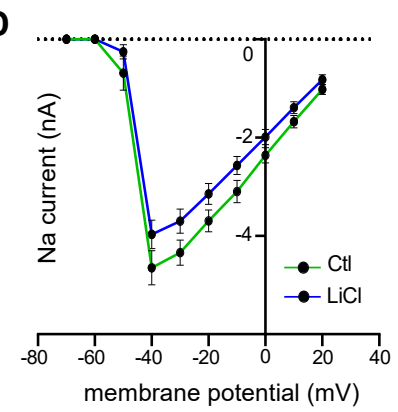

I

Ctl mEPSCs

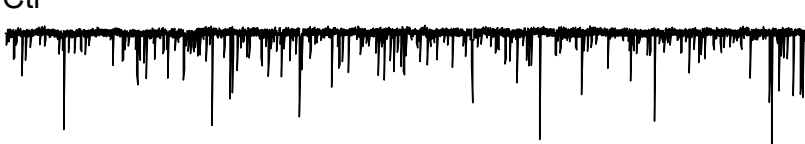

J

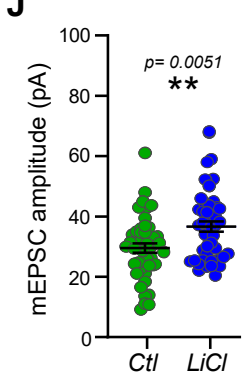

B

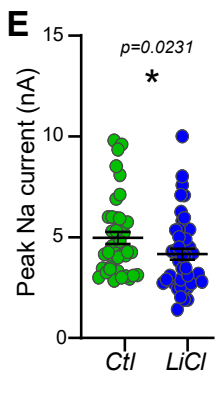

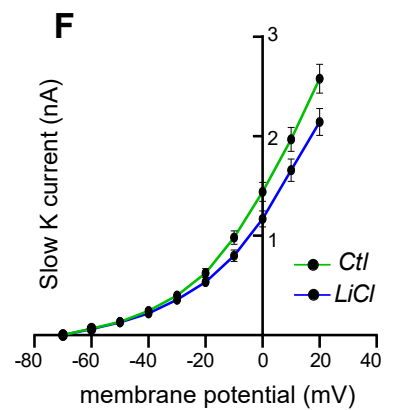

K

C

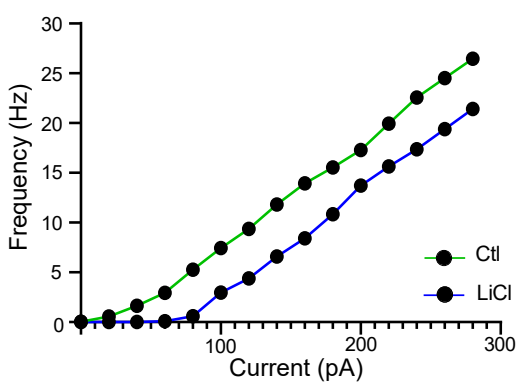

G

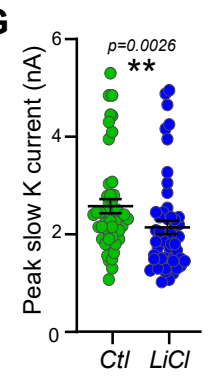

:

mIPSCs

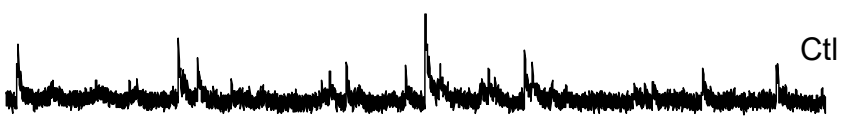

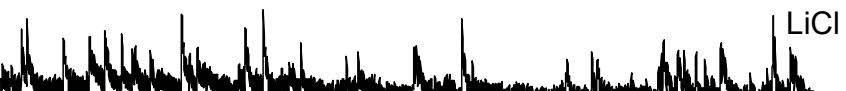

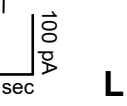

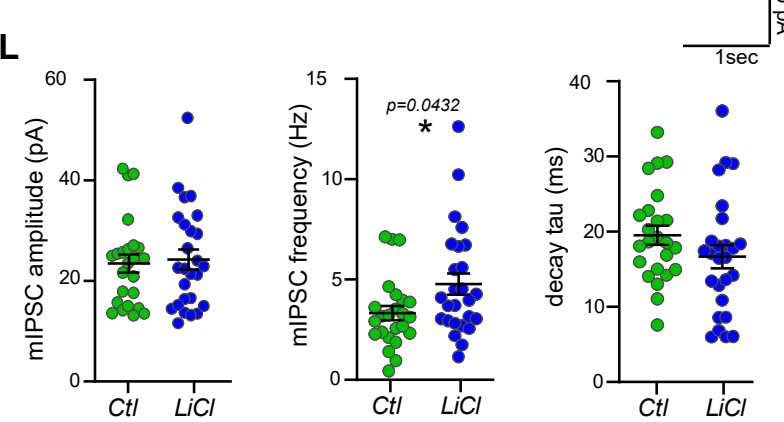



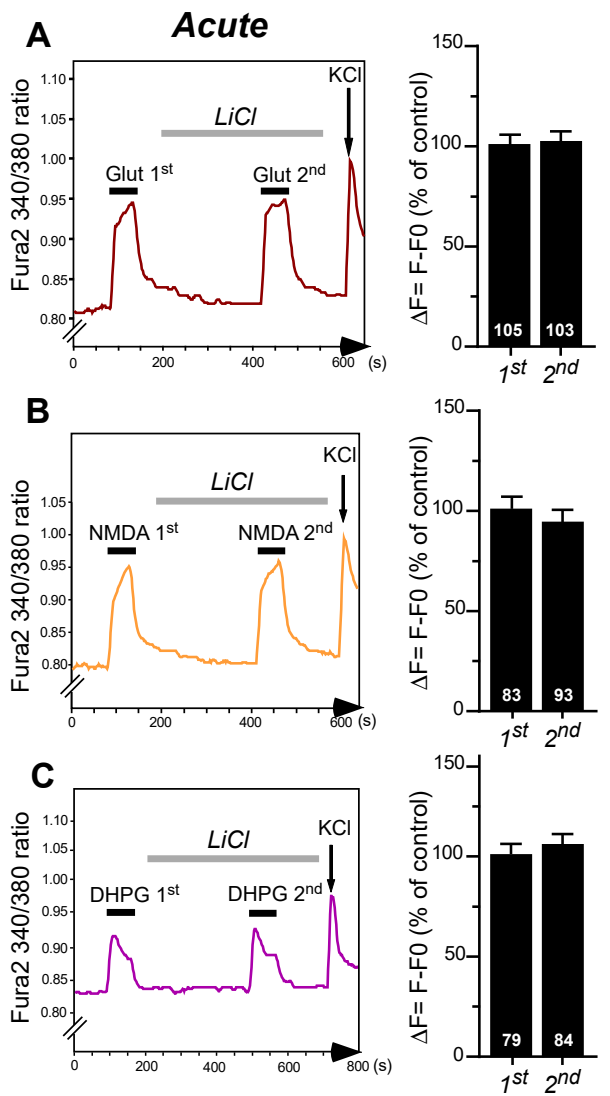

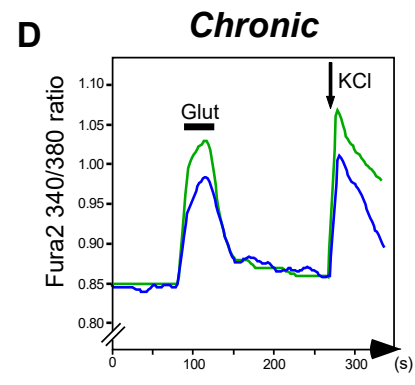

E
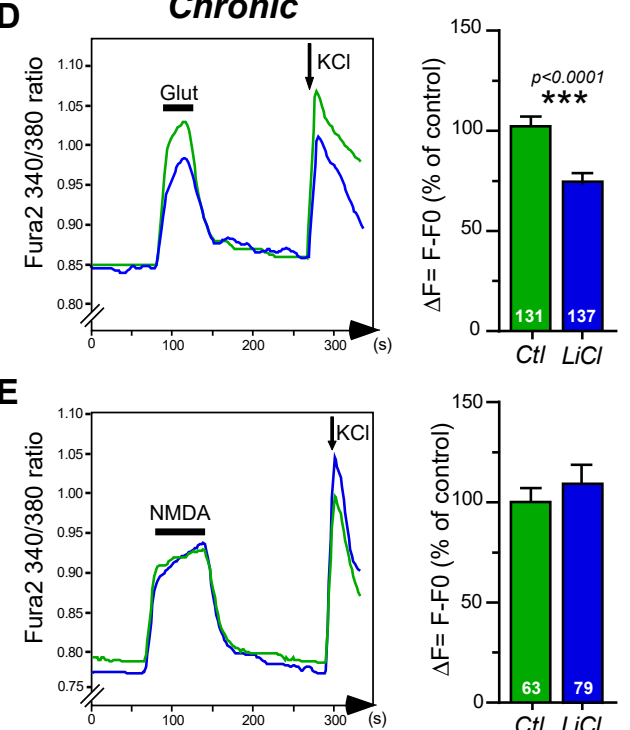

G

KDa: $C^{\dagger 1} \frac{L i C l}{251} 1^{0} v^{C l}$
phPKCC

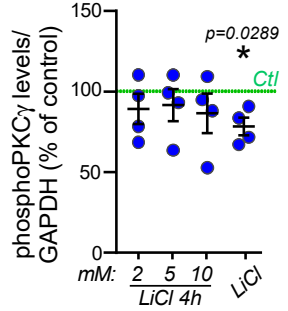

H

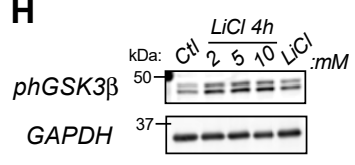
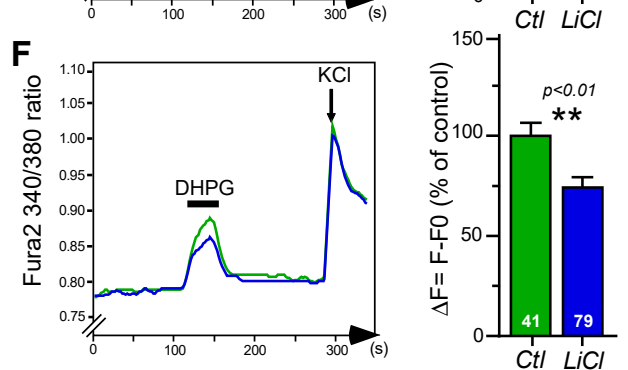

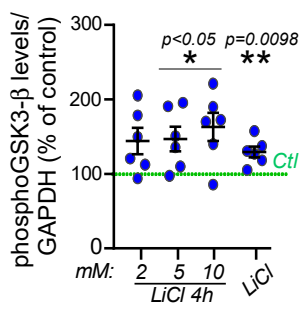

